\title{
BMJ Open Feasibility and tolerability of bone impact microindentation testing: a cross- sectional, population-based study in Australia
}

\author{
Pamela Rufus-Membere, ${ }^{1}$ Kara L Holloway-Kew, ${ }^{1}$ Adolfo Diez-Perez, ${ }^{2}$ \\ Mark A Kotowicz, ${ }^{1,3,4}$ Julie A Pasco $1,3,4,5$
}

To cite: Rufus-Membere $P$, Holloway-Kew KL, Diez-Perez A, et al. Feasibility and tolerability of bone impact microindentation testing: a cross-sectional, population-based study in Australia. BMJ Open 2018;8:e023959. doi:10.1136/ bmjopen-2018-023959

\section{- Prepublication history for} this paper is available online. To view these files, please visit the journal online (http://dx.doi. org/10.1136/bmjopen-2018023959).

Received 4 May 2018 Revised 13 October 2018 Accepted 26 October 2018
Check for updates

(C) Author(s) (or their employer(s)) 2018. Re-use permitted under CC BY-NC. No commercial re-use. See rights and permissions. Published by BMJ.

For numbered affiliations see end of article.

Correspondence to Mrs Pamela Rufus-Membere; prufus@deakin.edu.au

\section{ABSTRACT}

Objectives The 0steoProbe measures Bone Material Strength Index (BMSi) of cortical bone in living humans using impact microindentation (IMI). Research using this minimally invasive technique is expanding yet, to-date, there have been no reports about its feasibility in the research setting. In this study, we assessed the feasibility and tolerability of using the OsteoProbe in men enrolled in the Geelong Osteoporosis Study.

Design Cross-sectional analysis of data collected in a population-based study.

Setting Barwon Statistical Division, southeastern Australia, 2016-2018.

Methods For 252 of 345 consecutive participants (ages 33-96 years), BMSi was measured using the 0steoProbe at the mid-tibia. Immediately following measurement, each participant used a Visual Analogue Scale (0-10) to rate the level of discomfort that was anticipated and experienced, their initial reluctance towards the measurement and their willingness to repeat measurement.

Results Reasons for non-measurement in 92 men were needle phobia $(n=8)$, discomfort after first indentation $(n=5)$, skin infections $(n=21)$, excessive soft tissues around the mid-tibia region ( $n=56$ ), inability to provide informed consent ( $n=2)$. Among 252 men who had IMI measures, the expectation for pain during measurement was low $(1.54 \pm 1.56)$, as was actual pain experienced $(0.38 \pm 0.71)$. Reluctance to undergo measurement was low $(0.34 \pm 0.93)$. All participants indicated a willingness to have the measurement performed again. Mean $( \pm \mathrm{SD})$ BMSi was 83.0 \pm 6.4 (range 62.3-93.0).

Conclusion In this study, the procedure was well accepted by participants suggesting that IMI testing with the 0steoProbe is feasible in a research setting.

\section{INTRODUCTION}

The most widely used clinical measurement for ascertainment of fracture risk is bone mineral density (BMD) measured by dual-energy X-ray absorptiometry (DXA). ${ }^{1}$ However, BMD does not fully explain fracture risk, as the largest absolute number of fragility fractures occur in people without severe deficits in BMD. ${ }^{2} 3$ Other determinants of bone strength such as
Strengths and limitations of this study

Feasibility and tolerability were assessed at the time of impact microindentation (IMI) testing.

- The sample was selected at random from the general population and not on the basis of disease status.

- One operator conducted the IMI measurements.

- This is the first study to report the actual number of IMI exclusions due to contraindications.

- The findings might not be generalisable to women or other populations.

bone geometry, microarchitecture and material properties are likely to contribute to fracture risk. Also, clinical factors such as a history of prior fracture, age, exposure to glucocorticoid and other medications, smoking and falls, can contribute independently to fracture risk, and these risk factors can be incorporated into fracture risk algorithms such as Fracture Risk Assessment Tool (FRAX), ${ }^{4}$ the Garvan Fracture Risk Calculator ${ }^{5}$ and the Fracture Risk (FRISK) Score. ${ }^{6}$ Therefore, the goal of much research is to develop techniques to better identify patients at risk of fracture. One such technique is Impact Microindentation (IMI) which uses the OsteoProbe ${ }^{\circledR}$ to measure the material properties of cortical bone in vivo ${ }^{7}$ The OsteoProbe measures Bone Material Strength Index (BMSi). This parameter quantifies how well a bone resists microindentation. BMSi is defined as 100 times the ratio of the indentation distance from the impact to a calibration material, poly methyl methacrylate, divided by the indentation distance from the impact into the bone. As the probe indents the bone, it induces microfractures. The more easily the bone is fractured, the deeper the probe indents and the lower the BMSi. The technical aspects of this device have been described in detail in the initial scientific instrumentation papers. ${ }^{78}$ The use of this device in research is growing; and BMSi has 
reportedly distinguished between patients with different levels of fracture risk in some ${ }^{9-12}$ but not all ${ }^{13}$ studies, often independently of BMD. These studies have been limited to relatively small sample sizes and have often involved patients selected on the basis of disease.

Although these data suggest that BMSi might have clinical utility, future research is warranted, particularly using unselected, population-based samples, to assess the performance of IMI for identifying individuals at risk of fracture. As a new, minimally invasive technology, it is important to gauge the tolerability of the IMI to better understand whether participant groups and volunteers are likely to undergo the procedure in a research setting. The aim of this study was to assess the feasibility and tolerability of the OsteoProbe among men enrolled in the Geelong Osteoporosis Study (GOS).

\section{METHODS}

\section{Patient and public involvement}

Patients were not involved in the planning and design of this study.

\section{Source population}

The GOS is a population-based study situated in a defined region in southeastern Australia, known as the Barwon Statistical Division. ${ }^{14}$ An age-stratified, randomly selected cohort of 1540 men aged 20-97 years was recruited during 2001-2006 using the electoral roll as the sampling frame. The cohort is being followed prospectively, with assessments every few years. ${ }^{14}$ This analysis focuses on the first 345 men assessed as part of the 15-year follow-up. In conjunction with other clinical measures including bone densitometry, participants were approached to undergo IMI testing and complete a short questionnaire about their experience relating to the technique.

\section{Bone material strength testing}

IMI was performed by a trained operator using the OsteoProbe (Active Life Scientific; California, USA). The IMI procedure was explained to participants before measurements were made. They were informed that the procedure is a new technique that might assess the resistance of bones to fractures by inducing microfractures on a small area of the tibia. Furthermore, participants were told the procedure is minimally invasive and does not affect the ability of the individual to walk immediately after. They were then given the option to participate or not participate in the study.

Participants who chose to participate in the study were positioned in decubitus supine position, with the leg to be measured rotated to orient the flat surface of the medial tibia diaphysis. The mid distance between the medial border of the tibia plateau and the medial malleolus were marked using a measuring tape. Following a disinfection of the area using a $70 \%$ isopropyl alcohol swab, $2 \%$ Lidocaine was administered by inserting a syringe both subcutaneously and in the periosteal surface. A sterile probe was then inserted at the marked mid-diaphysis, piercing the skin and periosteum until reaching the bone cortex. While maintaining probe contact with the bone surface, as well as orienting the probe perpendicularly to the tibia surface, the outer housing of the device was slid towards the subject's leg to initiate a measurement. After the first measurement, the probe was moved to a new location, at least $2 \mathrm{~mm}$ away from the prior measurement, to obtain another measurement. In this study, at least 11 indentations were performed on each subject, of which the first measurement was systematically disregarded followed by 10 valid test indentations. A trained observer assisted the operator by ensuring that the probe was held perpendicular to the tibial surface. The procedure was conducted according to internationally-recognised recommendations for using the Osteoprobe RUO. ${ }^{15}$ Immediately following measurement, each participant completed a questionnaire that asked them to rate on a Visual Analogue Scale $(0-10)$ the level of pain that was anticipated, the level of pain that was experienced, their initial reluctance towards the measurement and their willingness to undergo the measurement again. The Visual Analogue Scale is a valid, reliable and simple tool used to assess variations in pain intensity ${ }^{1617}$

\section{Statistical analyses}

Comparisons between participants included in and excluded from the analyses were identified using t-tests, and one-way analysis of variance for differences in Visual Analogue Scale responses across age groups. Pearson product moment correlation was used to test for a linear correlation between BMSi and age, weight, height and body mass index (BMI). Statistical analyses were performed using Minitab V.17 (State College, Pennsylvania, USA).

\section{RESULTS}

Of 345 potential participants, exclusions were: needle phobia $(n=8)$, existing skin infections $(n=21)$, excessive soft tissues around mid-tibia region $(\mathrm{n}=56)$, due to discomfort (pressure, no pain) after the first indentation $(n=5)$, unable to provide informed consent $(n=2)$. One participant had IMI after treatment for skin infection. Therefore, 252 participants were included in the subsequent analyses.

Table 1 Characteristics of the study participants included in and excluded from the analyses

\begin{tabular}{lllc}
\hline Characteristics & $\begin{array}{l}\text { Included } \\
(\mathbf{n = 2 5 2})\end{array}$ & $\begin{array}{l}\text { Excluded } \\
(\mathbf{n = 9 2 )}\end{array}$ & P values \\
\hline Age (years) & $63.2 \pm 12.6$ & $65.5 \pm 15.6$ & 0.163 \\
\hline Weight $(\mathrm{kg})$ & $81.2 \pm 10.9$ & $92.9 \pm 19.1$ & $<0.001$ \\
Height $(\mathrm{cm})$ & $174.3 \pm 6.9$ & $173.7 \pm 10.3$ & 0.983 \\
\hline $\begin{array}{l}\text { Body mass index } \\
\left(\mathrm{kg} / \mathrm{m}^{2}\right)\end{array}$ & $26.7 \pm 3.1$ & $30.8 \pm 7.8$ & $<0.001$ \\
\hline
\end{tabular}

Data shown as mean $( \pm S D)$. 
Table 2 Tolerability scores for the whole group and according to age

\begin{tabular}{llllll}
\hline & ALL ages & 30-49years & 50-69years & 70+ years & P values \\
\hline Expectation for pain* $^{*}$ & $1.5 \pm 1.6$ & $2.0 \pm 1.7$ & $1.6 \pm 1.6$ & $1.2 \pm 1.5$ & 0.070 \\
Actual pain experienced $^{*}$ & $0.4 \pm 0.7$ & $0.4 \pm 0.8$ & $0.4 \pm 0.8$ & $0.3 \pm 0.5$ & 0.462 \\
Level of reluctance* $^{*}$ & $0.3 \pm 0.9$ & $0.6 \pm 1.0$ & $0.4 \pm 1.0$ & $0.2 \pm 0.6$ & 0.136 \\
\hline
\end{tabular}

${ }^{\star}$ Questionnaire results for 0-10 Visual Analogue Scale.

Table 1 shows characteristics of study participants included in and excluded from the analyses. Participants ranged in age from 33 to 96 years.

BMSi ranged from 62.3 to 93.0. Mean $\mathrm{BMSi} \pm \mathrm{SD}$ values

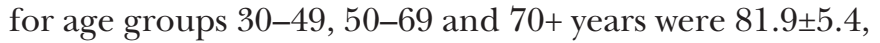
$83.7 \pm 6.2$ and $81.6 \pm 6.7$, respectively. The average BMI of participants excluded due to soft tissues was 33.4 5.6.

Tolerability scores were normally distributed and similar across all ages (table 2, figure 1). The expectation for pain during OsteoProbe measurement was low, as was actual pain experienced and initial reluctance to undergo measurement. Tolerability of the OsteoProbe measurement was high; all 252 participants who had a successful measurement indicated a willingness to undergo the measurement again. No adverse events were reported.

There were no correlations detected between BMSi and age $(r=0.070, p=0.270)$, height $(r=0.068, p=0.281)$ or weight $(\mathrm{r}=-0.078, \mathrm{p}=0.215)$; however, there was a negative correlation between BMSi and BMI $(\mathrm{r}=-0.135, \mathrm{p}=0.032)$.

\section{DISCUSSION}

In this study, we observed a high tolerability of IMI; reluctance to undergo the measurement was low, and while there may be a potential concern for possible harm to the bone, all participants who had a successful measurement indicated a willingness to undergo the measurement again.

Although IMI is a minimally invasive procedure, with indentations on the scale of micrometres, a valid concern is the tolerability of the procedure in a research setting, particularly in studies that rely on participants/volunteers from the general population. We report that testing with

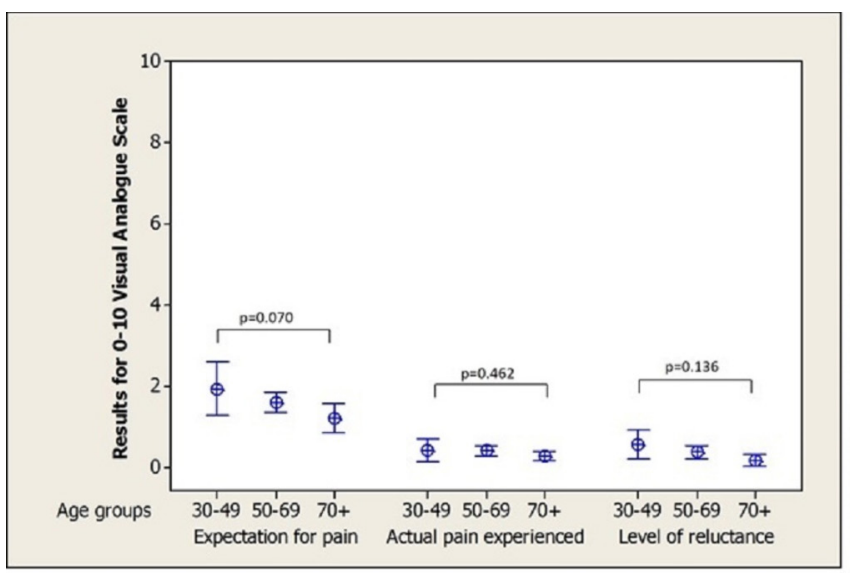

Figure 1 An interval plot of 0-10 Visual Analogue Scale results, according to age. the device is feasible among participants in our population-based study. The most common reason for exclusion was excessive soft tissues around the mid-tibia. Other reasons for exclusions were skin infections, needle phobia, inability to provide informed consent and discomfort after the first indentation, but these affected only one-tenth of the study participants. Other potential contraindications include prior clinical or stress fracture in the tibia diaphysis, focal tibial lesions and Paget's disease ${ }^{15}$; however, to the best of our knowledge, no studies have reported the actual number of exclusions based on these criteria.

In studies using IMI, only two instances of adverse effects have been reported in the literature, one associated with reaction to local anaesthetic and one mild skin infection, in more than 1300 measured individuals. ${ }^{15}$ To our knowledge, we are the first to document the tolerability of the procedure. Given that the anterior surface of the tibial is pretreated with a local anaesthetic delivered by subcutaneous injection through the skin and around the periosteum and that the probe of the device is inserted through the skin, subcutaneous soft tissue and periosteum into the cortical bone, it would seem likely that the procedure might seem unpleasant for some study participants. High rates of refusal would introduce bias. However, our results indicate that IMI is generally acceptable, at least for the participants of our study implying that the technique shows promise as a measure of bone material properties in a practical, safe and convenient manner.

Furthermore, we investigated participants from a wide age range and observed similar tolerability scores across age groups ranging from 30 to $49,50-69$ to 70 years and older. The men in the oldest category tended to report a lower expectation for pain, experienced less pain and were less reluctant to undergo the measurement, but these differences were not statistically significant.

In this study, we did not observe a correlation between BMSi and age, corresponding to two studies by Duarte Sosa $e t$ al in which no association was detected between age and BMSi in 42 Norwegian and 46 Spanish women ${ }^{18}$ and among 30 women with previous stress fractures and 30 normal controls. ${ }^{19}$ By contrast, an inverse association between age and BMSi has been reported for 90 patients (male and female) with low bone mass, $(\mathrm{r}=-0.539$; $\mathrm{p}<0.001)$ and in a case-control study of 48 patients with acromegaly and 44 controls (male and female), there was a positive association for patients with acromegaly $(\mathrm{r}=0.291, \mathrm{p}=0.045)$ and an inverse relationship for the controls $(r=-0.457, p=0.002) .{ }^{20}$ The reason for lack of 
consistency in results is not clear but likely reflects differences in study design and study populations.

Moreover, no correlations of BMSi with height, weight were found but we observed a negative correlation between BMSi and BMI. Similarly, Sundh $e t a l^{21}$ reported a negative correlation $(\mathrm{r}=-0.17, \mathrm{p}=0.01)$ between $\mathrm{BMSi}$ and BMI in a population-based study of 202 women between 75 and 80 years of age, and Rudang et $a l^{13}$ reported a weak inverse correlation $(r=-0.14, p=0.04)$ between $B M S i$ and weight in a population-based cohort of 211 women between 75 and 80 years of age, and, in accordance with our findings, there was no association with height.

To our knowledge, this is the first study to examine the tolerability and feasibility of the OsteoProbe in a population-based study. Unlike most of the previous studies, this study is population-based and not selected on the basis of disease status. The outcome will thus be relevant for the general population. In this study, one operator conducted the IMI measurements, and an observer was present to ensure the procedure was performed according to the standardised procedure.

However, we acknowledge the following limitations. IMI could not be performed in individuals with substantial amounts of soft tissue around the mid-tibia region, nor in individuals with skin disorders or infections in at the site of measurement and this may have biased our results. It should be noted that there are also drawbacks with other technologies. For example, a weight limitation (typically $120 \mathrm{~kg}$ or $300 \mathrm{lb}$ ) and narrow bed width $(\sim 60 \mathrm{~cm})$ necessitates exclusion of large individuals from assessment with DXA. ${ }^{22}$ Furthermore, individuals with spinal abnormalities and those affected by devices such as plates, screws, silicone implants and prostheses can compromise the interpretation of DXA scans. ${ }^{23-26} \mathrm{In}$ our study, we investigated men only, and recognise that the observations may not be generalisable to women or other populations.

In conclusion, IMI was well accepted by participants suggesting that testing with the OsteoProbe is feasible in a research setting. Further assessment of the clinical utility of this technology for assessing fracture risk is warranted and currently in progress.

\section{Author affiliations}

${ }^{1}$ School of Medicine, Deakin University, Geelong, Victoria, Australia

${ }^{2}$ Department of Internal Medicine, Hospital del Mar-IMIM, Autonomous University of Barcelona and CIBERFES, Instituto Carlos III, Madrid, Spain

${ }^{3}$ Department of Medicine-Western Health, The University of Melbourne, Melbourne, Victoria, Australia

${ }^{4}$ University Hospital Geelong, Barwon Health, Geelong, Victoria, Australia

${ }^{5}$ Department of Epidemiology and Preventive Medicine, Monash University,

Melbourne, Victoria, Australia

Acknowledgements The authors thank Dr Peter Burks from Active Life Scientific, Inc. for his technical guidance

Contributors PGR performed the indentation measurements in the presence of another trained observer $(\mathrm{KLH}-\mathrm{K})$ and drafted the manuscript. KLH-K assisted with taking measurements and administered questionnaires. AD-P assisted with training to use the OsteoProbe device and provided advice on measurement technique. MAK and JAP conceived and designed the study. JAP secured ethics approval. All authors interpreted the data, guided and reviewed the manuscript. All authors read and approved the final manuscript.

Funding The Geelong 0steoporosis Study was supported by the National health and Medical Research Council (NHMRC; projects 299831, 628582) and Amgen-GSK OA-ANZBMS, but they played no role in the collection or interpretation of data.

Competing interests PGR is supported by Deakin University Postgraduate Industry Research Scholarship. KLH-K is supported by an Alfred Deakin Postdoctoral Research Fellowship. AD-P owns shares of Active Life Scientific, Inc., the manufacturer of the RPI device. MAK and JAP are recipients of grants from the NHMRC and Amgen-GSK OA-ANZBMS.

Patient consent for publication Obtained.

Ethics approval This project has been approved by Human Research Ethics Committee at Barwon Health.

Provenance and peer review Not commissioned; externally peer reviewed.

Data sharing statement The datasets used and analysed during the current study are available from the corresponding author on reasonable request. Requests can be sent to gos@barwonhealth.org.au.

Open access This is an open access article distributed in accordance with the Creative Commons Attribution Non Commercial (CC BY-NC 4.0) license, which permits others to distribute, remix, adapt, build upon this work non-commercially, and license their derivative works on different terms, provided the original work is properly cited, appropriate credit is given, any changes made indicated, and the use is non-commercial. See: http://creativecommons.org/licenses/by-nc/4.0/.

\section{REFERENCES}

1. Blake GM, Fogelman I. The role of DXA bone density scans in the diagnosis and treatment of osteoporosis. Postgrad Med J 2007;83:509-17.

2. Pasco JA, Seeman E, Henry MJ, et al. The population burden of fractures originates in women with osteopenia, not osteoporosis. Osteoporos Int 2006;17:1404-9.

3. Pasco JA, Lane SE, Brennan SL, et al. Fracture risk among older men: osteopenia and osteoporosis defined using cut-points derived from female versus male reference data. Osteoporos Int 2014;25:857-62.

4. Watts NB. The Fracture Risk Assessment Tool (FRAX): applications in clinical practice. J Womens Health 2011;20:525-31.

5. Nguyen ND, Frost SA, Center JR, et al. Development of a nomogram for individualizing hip fracture risk in men and women. Osteoporos Int 2007;18:1109-17.

6. Henry MJ, Pasco JA, Sanders KM, et al. Fracture Risk (FRISK) Score: Geelong Osteoporosis Study. Radiology 2006;241:190-6.

7. Randall C, Bridges D, Guerri R, et al. Applications of a New Handheld Reference Point Indentation Instrument Measuring Bone Material Strength. J Med Device 2013;7:041005-6.

8. Bridges D, Randall C, Hansma PK. A new device for performing reference point indentation without a reference probe. Rev Sci Instrum 2012;83:044301-8.

9. Malgo F, Hamdy NA, Papapoulos SE, et al. Bone material strength as measured by microindentation in vivo is decreased in patients with fragility fractures independently of bone mineral density. J Clin Endocrinol Metab 2015;100:2039-45.

10. Malgo F, Hamdy NAT, Papapoulos SE, et al. Bone material strength index as measured by impact microindentation is low in patients with fractures irrespective of fracture site. Osteoporos Int 2017;28:2433-7.

11. Rozental TD, Walley KC, Demissie S, et al. Bone Material Strength Index as Measured by Impact Radius and Hip Fractures. J Bone Miner Res 2017;176:1-6.

12. Rozental TD, Walley KC, Demissie S, et al. Bone Material Strength Index as Measured by Impact Microindentation in Postmenopausal Women With Distal Radius and Hip Fractures. J Bone Miner Res 2018;33:621-6.

13. Rudäng $R$, Zoulakis $M$, Sundh $D$, et al. Bone material strength is associated with areal BMD but not with prevalent fractures in older women. Osteoporos Int 2016;27:1585-92.

14. Pasco JA, Nicholson GC, Kotowicz MA. Cohort profile: Geelong Osteoporosis Study. Int J Epidemiol 2012;41:1565-75.

15. Diez-Perez A, Bouxsein ML, Eriksen EF, et al. Technical note: Recommendations for a standard procedure to assess cortical bone at the tissue-level in vivo using impact microindentation. Bone Rep 2016;5:181-5.

16. Chapman $\mathrm{CR}$, Casey $\mathrm{KL}$, Dubner R, et al. Pain measurement: an overview. Pain 1985;22:1-31. 
17. Gallagher EJ, Bijur PE, Latimer C, et al. Reliability and validity of a visual analog scale for acute abdominal pain in the ED. Am J Emerg Med 2002;20:287-90.

18. Duarte Sosa D, Vilaplana L, Güerri R, et al. Are the High Hip Fracture Rates Among Norwegian Women Explained by Impaired Bone Material Properties? J Bone Miner Res 2015;30:1784-9.

19. Duarte Sosa D, Fink Eriksen E. Women with previous stress fractures show reduced bone material strength. Acta Orthop 2016;87:626-31.

20. Malgo F, Hamdy NA, Rabelink TJ, et al. Bone material strength index as measured by impact microindentation is altered in patients with acromegaly. Eur J Endocrinol 2017;176:339-47.

21. Sundh $D$, Rudäng $R$, Zoulakis $M$, et al. A high amount of local adipose tissue is associated with high cortical porosity and low bone material strength in older women. $J$ Bone Miner Res 2016;31:749-57.
22. Rothney MP, Brychta RJ, Schaefer EV, et al. Body composition measured by dual-energy $\mathrm{X}$-ray absorptiometry half-body scans in obese adults. Obesity 2009;17:1281-6.

23. Gould H, Brennan SL, Kotowicz MA, et al. Total and appendicular lean mass reference ranges for Australian men and women: the Geelong osteoporosis study. Calcif Tissue Int 2014;94:363-72.

24. Henry MJ, Pasco JA, Korn S, et al. Bone mineral density reference ranges for Australian men: Geelong Osteoporosis Study. Osteoporos Int 2010;21:909-17.

25. Kalichman L, Li L, Kim DH, et al. Facet joint osteoarthritis and low back pain in the community-based population. Spine 2008;33:2560-5.

26. Szulc P, Marchand F, Duboeuf F, et al. Cross-sectional assessment of age-related bone loss in men: the MINOS study. Bone 2000;26:123-9. 